\title{
Interrelation of career anchors with education and labor activity motives of students
}

\author{
Anna Sheveleva * and Irina Pankratova \\ Southern Federal University, 344006, Rostov-on-Don, Russian Federation
}

\begin{abstract}
The article is devoted to the research of career orientations (career "anchors") with education and labor activity motivation of students. 114 students of "Psychological and pedagogical education" took part in the study. It is revealed that the most adequate motivation of education expressed in the predominance of motives for acquiring knowledge and mastering the profession is associated with career orientations "service / dedication to a cause", "pure challenge", "technical / functional competence". In other words, it is connected with aspiration to realize basic values in their careers, to improve the world, to develop and apply professional skills, to solve difficult problems, to overcome obstacles, to win. The career anchor of "service / dedication to a cause" is also associated with an increase of the communicative motive and a decrease of the competitive motive of labor activity. The more students are guided by the formal motive of getting a diploma of higher education, the less the stability of a career is valuable for them. The more utilitarian and pragmatic motive of labor activity is expressed in students, the less they are inclined to managerial or entrepreneurial career. The more autonomy and independence in career is valuable for students, the less social usefulness of labor (cooperative motive) is important for them.
\end{abstract}

The potential of higher education as a career start for modern young people covers much more than the opportunity to acquire the chosen specialty. At the same time it is possible to build different meanings even within one profession. They determine what is attractive to a person in the profession, in what sphere he wants to specialize or what aspects of the profession are undesirable for him. Personal creations in the form of motives, goals, values regarding the educational and professional and labor activities are realized, updated and developed in the process of students studying at the university. They inevitably find reflection in further career development [1]. As pointed out by the author of the concept of career anchors Edgar Schein [2], each person has attitudes about what is important for him in his professional career - career anchors or career orientations. They are an element of the Selfconcept, they serve as a stabilizing force, as an anchor. Career anchors motivate for career choices during the whole life, determine and help to keep the direction of career development. Their content includes an idea about their abilities, values, developed system of motives and needs for a career, from which a person will not give up being forced to make a

\footnotetext{
* Corresponding author: amsheveleva@sfedu.ru
} 
choice.

The aim of this research was to identify the interconnection of career orientations and related to educational and labor activities motives of students of psychological and pedagogical education. The hypothesis of the existence of interrelations of career orientations with the motives of education and labor activity was tested.

The study involved of full-time university students of psychological and pedagogical education from different years in the amount of 114 people, male and female in the age from 17 to 21 years.

The following psychodiagnostic techniques were used:

- "Career Anchors Questionnaire" by E. Shein. It reveals career orientations or anchors: technical / functional competence, general managerial competence, autonomy / independence, security / stability, service / dedication to a cause, pure challenge, lifestyle, entrepreneurial creativity.

- "The technique of studying the motives of education in high school" by T.I. Ilyina. It diagnoses the following motives: "acquiring knowledge", "mastering the profession" and "getting a diploma".

- The technique of studying the motivation of labor activity "Dictionary" by I.G. Kokurina. It is aimed at identifying of six of sense making motives: transformative, communicative, utilitarian and pragmatic, cooperative, competitive, the motive of achievement. In addition, it is possible to find two types of orientation of each of the motives: resultant and procedural.

To process the results of the study the statistical methods (Spearman correlation analysis, Friedman criterion, Mann-Whitney criterion) were used. The results at the significance level $\leq 0.05$ were taken as statistically reliable and were subjected to further analysis and interpretation.

It was found that there are significant differences in the preference of career orientations in the sample of students. Three of them are mostly expressed - "Service / dedication to a cause ", "Lifestyle", "General managerial competence" (listed in descending order). Career orientation "Technical / functional competence" was rejected. So for students of psychological and pedagogical education the most important guides in their careers were the opportunity to realize their own basic values through devotion to their work and helping people, the balance of different spheres of life and roles (family, work, self-development), the desire to manage and organize the activities of other people. At the same time the achievement of skill and development of abilities is rarely considered as an indicator of success.

After analyzing the motives of studying at the university at the sample we identified their hierarchy. According to the descending of preference the motives are arranged in the following order: "getting a diploma", "acquiring knowledge", "mastering the profession". Thus studying at the University most of the respondents are firstly focused on the diploma as a formal confirmation of their higher education. At that roundabout ways in passing tests and examinations are considered to be acceptable. In its turn the desire to acquire professional knowledge and form professionally important qualities is present in the sample at an insufficient level. T.I. Ilyina, the author of the applied technique of diagnosis of motives of education at the university, considers motivational complex in which indicators of motives for acquiring knowledge and mastering the profession are dominated to be adequate. In the studied sample only $11 \%$ of the respondents are characterized by the predominance of these two motives. As for the rest of the respondents, it can be concluded that the motivational component of education is deformed.

It can be assumed that students oriented mainly on getting a diploma do not associate their future professional activity with the specialty they are studying. Probably, the choice of psychological and pedagogical education for them was connected with other, nonprofessional interests and was substantiated by considerations of the usefulness of the 
knowledge for everyday life, communication, interpersonal interaction, self-improvement.

The expressiveness of the motives of labor activity also varies at a statistically significant level. The leading motives are cooperative, communicative and achievement motive. At the same time in a cooperative motive and the motive of achievement there is a significant dominance of procedural orientation connected with the orientation for the needs of their close environment and developing themselves. The transformative motive - activity for the sake of activity itself, the result for the sake of the result itself - is rejected. Thus, the driving forces of labor activity for students of psychological and pedagogical education are ideas about the usefulness of their own work for people, society in general and especially for relatives and friends, communication and interaction with people, positive attitudes and helping people, the desire for self-improvement in the process of work.

Correlation interrelations of indicators of career orientations with indicators of motives of education and work were revealed (Fig. 1).

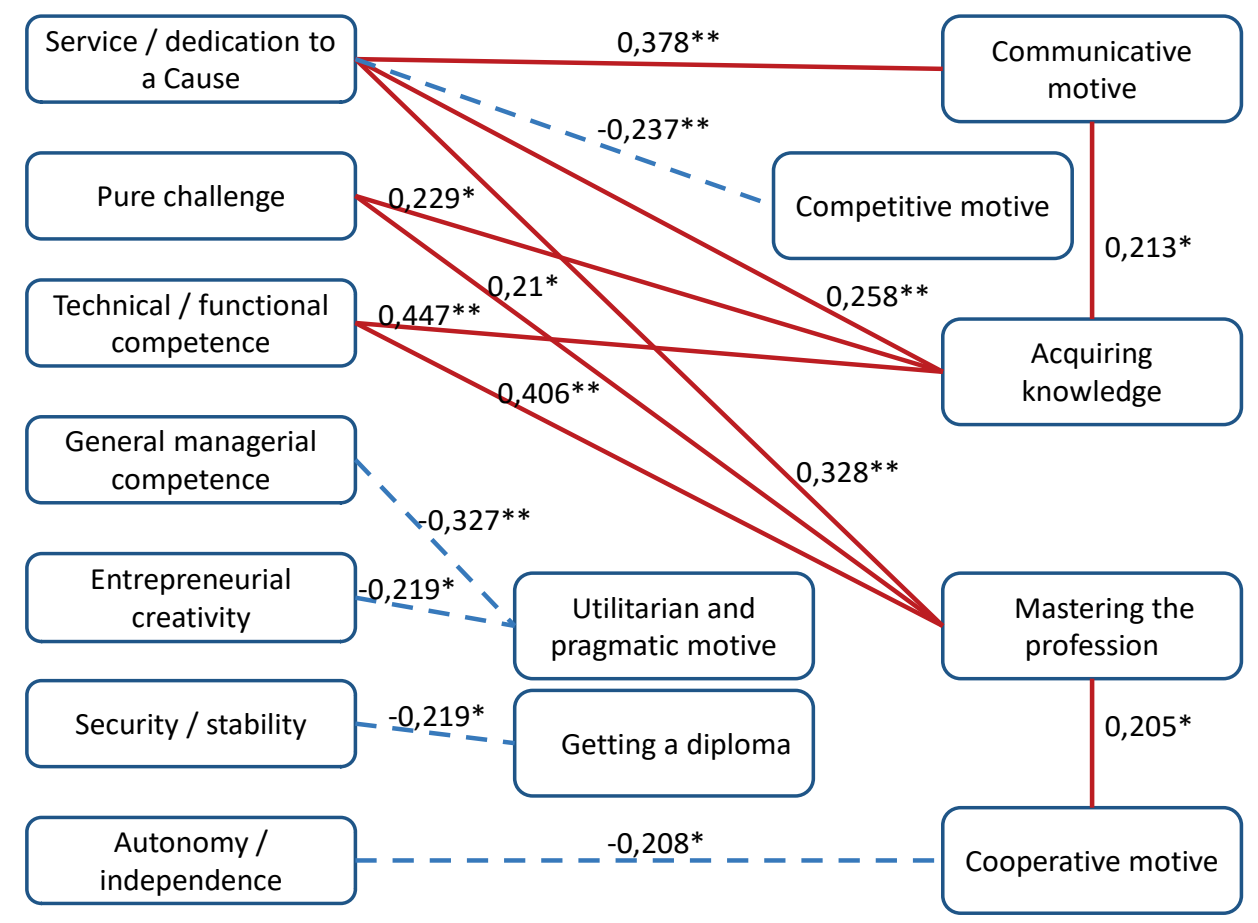

Fig. 1. Significant correlation of the studied indicators. (Spearman correlation coefficient, $* *$ - the significance level of the result $\leq 0.01, *$ - the significance level of the result $\leq 0.05$ )

So the leading career orientation "service / dedication to a cause" at the sample has the greatest number of correlations with the motives of education at the university and motives of labor activity. The direct relationship with the motives of acquiring knowledge and mastering the profession with the communicative motive was revealed. This career orientation is inversely correlated with the competitive motive. That is a career focused on the basic values of the personality, dedication to cause, working with people, serving humanity, helping people, the desire to make the world better, is agreed with the motivation aimed at communication, establishing and maintaining contacts between people, curiosity and the desire to acquire knowledge, professional skills, the formation of professionally important qualities in the psychological and pedagogical field. With the increase of the expressiveness of this career orientation the competitive motive as a tendency to compare oneself with oth- 
ers, demonstration of high status and superiority, decreases.

The career orientation "technical / functional competence" is less expressed at the sample, but finds the closest direct relationship with the indicators of motives of the education - "the acquiring knowledge" and "mastering the profession ". The career orientation "pure challenge" is directly connected with the same motives.

Thus, career orientations "service / dedication to a cause", "pure challenge" and "technical / functional competence" have the greatest motivational content. Students who value in the career to serve the chosen work and help people, to be high-class specialists, to develop their skills, to be able to solve difficult, not everyone available professional tasks, to overcome obstacles - are the most adequately motivated for education students.

Career orientations "general managerial competence" and "entrepreneurial creativity" are the more expressed, the less important is the utilitarian and pragmatic motive of labor activity. That is, students who are inclined to manage and organize the work of other people, to take full responsibility for the common cause, to occupy a leadership position, to create their own enterprise, ready to develop new business projects, least of all try to reduce their labor costs and get personal benefit from their work. In their turn, students for whom it is important to save their strength, energy and keep health, to meet the needs not directly related to the work, are less inclined to a career associated with management and entrepreneurial activity. So it can be concluded that the currently popular orientation of professional education on the development of entrepreneurial and managerial skills and the readiness to realize them in professional activities is not suitable for everyone. This fact should be taken into account when consulting on the questions of building of individual educational trajectory and professional career.

The more expressed the career orientation of "autonomy / independence", the smaller the value of cooperative motive of labor activity. That is, the higher the student's intention to do everything in his own way, to achieve freedom from control and restrictions, freedom in decision-making and choice of actions, independence from the organization and other people's rules, the less he is inclined to be guided by the motive of cooperation as a public usefulness of his work.

With the growth of career orientation "Security / stability" the importance of the education "getting a diploma" decreases. Thus, students, for whom only formal confirmation of higher education is important, are probably ready to respond flexibly to the changing situation in the labor market, to take risks and are not inclined to ensure their stable and reliable employment in one profession and in one organization, to "root", predictability of work and structured labor tasks. Perhaps such students believe that the advantages in the labor market are provided not so much by the quality and content of the received professional education as by the formal status of a "person with higher education".

Career orientation "lifestyle" - the desire to balance work with other spheres of life which took the second place by the degree of expressiveness at the sample did not reveal significant correlations with the indicators of motives. On this basis we believe that the motivational content of this orientation is heterogeneous and does not allow to identify a single trend.

Correlation interrelations between indicators of motives are found (Fig. 1). Thus, the motive of acquiring knowledge has a direct relationship with the communicative motive. And the motive of mastering the profession is directly related to the motive of cooperation. So the students of psychological and pedagogical education tend mainly to the knowledge that can make them successful in society, in establishing contacts and positive relationships with people. They consider the received profession as a means to benefit the people around them.

It is interesting that the indicator of the motive of "getting a diploma" which has the highest expressiveness at the sample found only one significant correlation. This motive is 
inversely correlated with the career orientation "security / stability" (see above). We can assume from this that students focused only on formal getting the status of a person with higher education have vague ideas about what is important for them in their studies, profession, career.

Interpretation of the obtained data allows us to identify the main trends in the sample of students of psychological and pedagogical education: professionally oriented and unprofessionally oriented.

Professionally oriented trend. The career orientations "service / dedication to a cause", "pure challenge", "technical / functional competence" are motivationally supported to the greatest extent. The most adequate complex of education motivation is connected with them - the motives of acquiring knowledge and mastering the profession. That is, the students who in their careers are focused on the implementation of fundamental values, dedication to their work and helping people, solving difficult professional problems and overcoming obstacles, development and improvement of skills are included in the study most of all. The main motivation of labor activity is determined by ideas about the usefulness of their own work for people, society and their closest environment, the possibility of working with people and creating positive relationships, as well as the desire for self-improvement in the process of work.

Unprofessionally oriented trend. According to the statistical results this trend prevails in the sample. It is expressed in the fact that many students intend to receive a diploma as a formal confirmation of higher education, do not have a clear system of ideas about what determines the value of their profession and career. Probably they do not associate their professional career with the received specialty and choose the direction of education on the basis of non-professional interests.

The combination of professionally oriented and unprofessionally oriented trends. The attractiveness of the choice of psychological and pedagogical education for students is connected with the opportunity not only to become a professional in this field, but also to acquire useful knowledge for the development of their own communicative success, skills of interpersonal interaction, establishing and keeping positive contacts with people. Students represent the received specialty as the one able to benefit both society as a whole and their closest environment. It is possible to assume that in future students are planning to apply their professional psychological knowledge not only in a profession, but also in everyday life for favorable establishment of friendly, romantic, family and other interpersonal contacts and the solution of own psychological problems.

The data obtained in the study can be used in psychological support of school-leavers and students on the choice of professional education, building an individual educational trajectory, in solving the problems of psychological readiness for professional activity, career planning.

\section{References}

1. E.E. Rogova, I.A. Pankratova, S.V. Zholudeva, A.M. Sheveleva, M.V. Naumenko, N.E. Skrynnik, International Journal of Environmental and Science Education, 11, 10137-10153, (2016)

2. E.H. Schein, The Academy of Management Executive, 10, 80-88, (1996) 